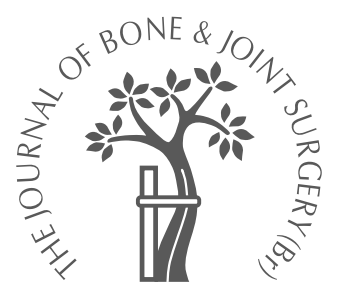

C. Baki,

M. Sener,

H. Aydin,

M. Yildiz,

S. Saruhan

From Karadeniz

Technical University, Trabzon, Turkey
C. Baki, MD, Professor, Chairman

M. Sener, MD, Associate Professor

H. Aydin, MD, Assistant Professor

M. Yildiz, MD, Professor

S. Saruhan, MD, Resident Department of Orthopaedics and Traumatology, Karadeniz Technical

University Medical School, 61080 Trabzon, Turkey.

Correspondence should be sent to Professor M. Sener at K T U Tip Fak, Ortopedi ve Travmatoloji AbD, 61080

Trabzon, Turkey; e-mail: msener87@yahoo.com

C2005 British Editorial Society of Bone and Joint Surgery doi:10.1302/0301-620X.87B3. $14663 \$ 2.00$

$J$ Bone Joint Surg [Br] 2005;87-B:380-3.

Received 2 June 2003;

Accepted after revision

7 January 2004

\title{
Single-stage open reduction through a medial approach and innominate osteotomy in developmental dysplasia of the hip
}

We treated 15 hips (15 patients) with developmental dysplasia by a single-stage combination of open reduction through a medial approach and innominate osteotomy. The mean age of the patients at the time of operation was 20 months (13 to 30). The mean follow-up period was 9.6 years ( 4 to 14 ).

At the final follow-up, 14 hips were assessed clinically as excellent and one hip as good. Radiologically, ten hips were rated as class I, four as class II and one as class III according to the criteria of Severin. No avascular necrosis was seen. No patient required subsequent surgery. Our results indicate that satisfactory results can be obtained with the single-stage combination of open reduction by the medial approach and innominate osteotomy for developmental dysplasia of the hip in a selected group of children older than $\mathbf{1 2}$ months. To our knowledge, no similar combined technique has been previously reported.

Patients with developmental dysplasia of the hip who cannot be managed conservatively require surgical treatment. Open reduction through a medial approach has been used in children younger than 24 months of age, ${ }^{1}$ but the results are more satisfactory in those aged 12 months or younger. ${ }^{2-4}$ The method is simple, atraumatic and safe with minimal softtissue dissection and no blood loss. ${ }^{1,2,5,6}$ Both hips can be operated on at the same session.

After 18 months of age, the structural changes around a dislocated hip which prevent concentric reduction increase. In such hips, the medial approach has two important disadvantages. First, capsulorrhaphy for preventing recurrent dislocation or subluxation cannot be performed and secondly, acetabular osteotomy which may be indicated for acetabular dysplasia is also not an option.

However, Salter's innominate osteotomy has been recommended and widely used in patients older than 18 months. ${ }^{7-10}$ In this technique, acetabular osteotomy and open reduction with capsulorrhaphy can be performed through an anterolateral approach.

In this study, we report the results of open reduction through a medial approach combined with innominate osteotomy in a single session in patients older than 12 months of age who had an acetabular angle greater than $35^{\circ}$ on pre-operative radiographs and/or instability at the end of their open reduction. We measured the acetabular, centre-edge (CE) and fem- oral neck-shaft angles at the end of the first and second post-operative years to assess the development of the hip.

\section{Patients and Methods}

Between 1988 and 1998, we treated 15 hips (15 patients) with developmental dysplasia of the hip by a combination of open reduction through a medial approach and innominate osteotomy. Teratological, paralytic and pathological dislocations were excluded. At the time of operation the mean age of the patients was 20 months (13 to 30). All the patients were girls. Both hips were dislocated in three patients, the left hip in seven and the right hip in five. In bilaterally dislocated patients, innominate osteotomy was performed on one side only after bilateral open reduction, the second side being operated on later.

In all hips, the position of maximum stability was assessed at the time of open reduction. The hips which required flexion with abduction for stability and/or had an acetabular angle above $35^{\circ}$ on the pre-operative radiograph, were judged to require an innominate osteotomy.

No patient had preliminary traction or previous treatment. The mean follow-up period was 9.6 years ( 4 to 14$)$.

Operative technique. A medial approach was made through a longitudinal incision between adductor longus and gracilis. By blunt dissection the lesser trochanter was exposed and an 


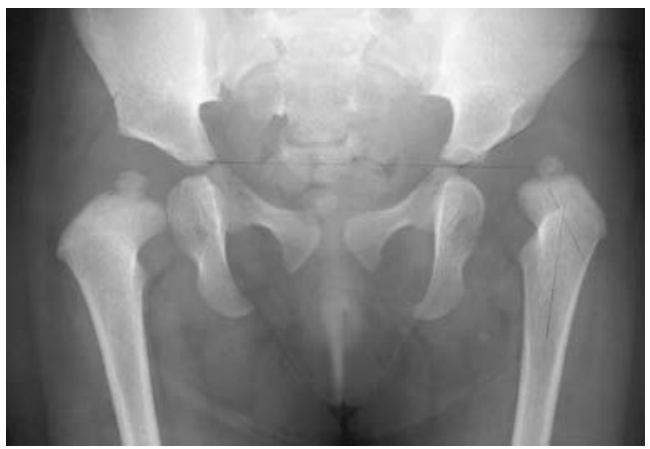

Fig. 1a

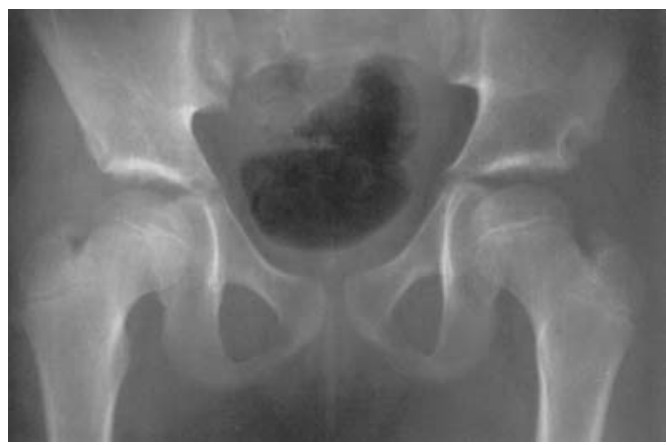

Fig. 1c

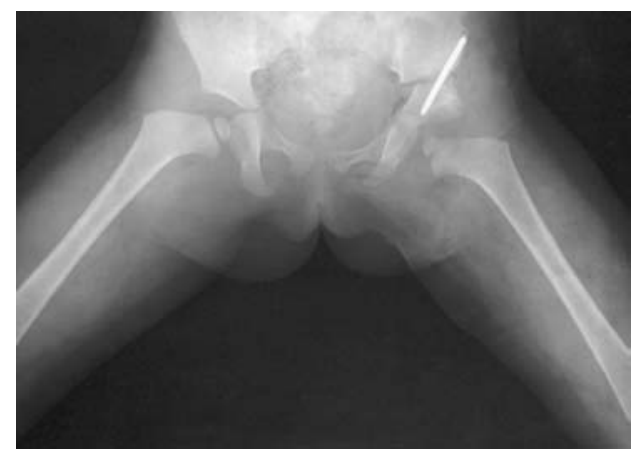

Fig. 1b

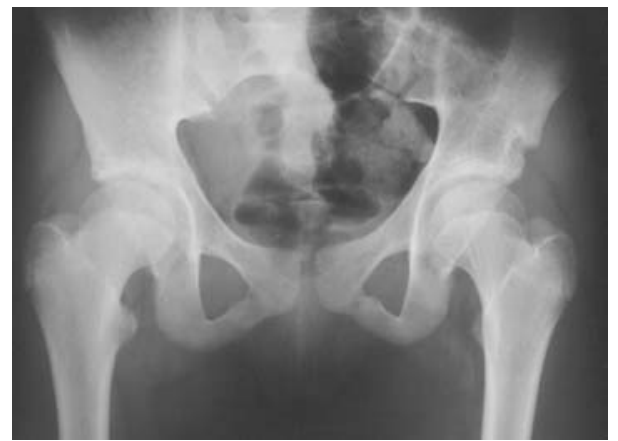

Fig. 1d

Radiographs of a 13-month-old girl with bilateral hip dysplasia and dislocation on the left side showing a) the preoperative view; b) after open reduction through a medial approach and a left innominate osteotomy with the right hip being treated conservatively; c) the anteroposterior view seven years later, and d) 12 years later with excellent results clinically and radiologically.

iliopsoas tenotomy performed. The capsule was opened longitudinally and inferomedially. Great care was taken to retract and avoid damage to the medial femoral circumflex vessels which crossed the operative field. The transverse acetabular ligament was divided and the pulvinar removed if hypertrophied. After reduction of the femoral head into the acetabulum, the stability of the hip was tested in various directions. An innominate osteotomy was then carried out, if indicated by the criteria stated above, through an anterolateral approach without capsulorrhaphy. The stability of the operated hip was retested after the osteotomy in the walking position. A hip spica cast was then applied for six weeks with the hip in $20^{\circ}$ of flexion, $30^{\circ}$ of abduction and $10^{\circ}$ of internal rotation. After removal of the cast, an abduction brace was routinely used at all times for three months.

We used for clinical assessment, McKay's criteria as modified by Berkeley et al, ${ }^{11}$ and Severin's criteria for radiological assessment. ${ }^{12}$ We evaluated the position of the femoral capital ossification centre on the pre-operative radiograph by the method of Tönnis. ${ }^{13}$ According to this grading system 11 hips were grade II, two were grade III and two grade IV. The acetabular, CE and femoral neckshaft angles were measured on pre-operative radiographs, and on those taken at the end of the first and second years, to assess the early development of the hip. The most lateral point of the subchondral condensation of the acetabular roof was used as a landmark in the measurement of the acetabular angle. The CE angle was measured as described by Ogata et al. ${ }^{14}$ The presence of avascular necrosis was determined using the criteria described by Salter, Kostuik and Dallas. ${ }^{15}$ Leg length was measured on physical examination from the anterior superior iliac spine to the medial malleolus and, after innominate osteotomy, from the umbilicus to the medial malleolus.

\section{Results}

There were no post-operative infections and concentric reduction was obtained at the time of operation in all hips (Fig. 1). No patient required subsequent surgery.

At the final follow-up, the clinical results were rated as excellent in 14 hips and good in one. On radiological assessment, ten hips were rated class I, four as class II and one as class III (Fig. 2).

The mean acetabular, CE and femoral neck-shaft angles are shown in Table I.

No avascular necrosis of the femoral head was observed. Temporary irregular ossification of the femoral head was noted in one hip which resolved completely without deformity. The hip was considered to be clinically good and 


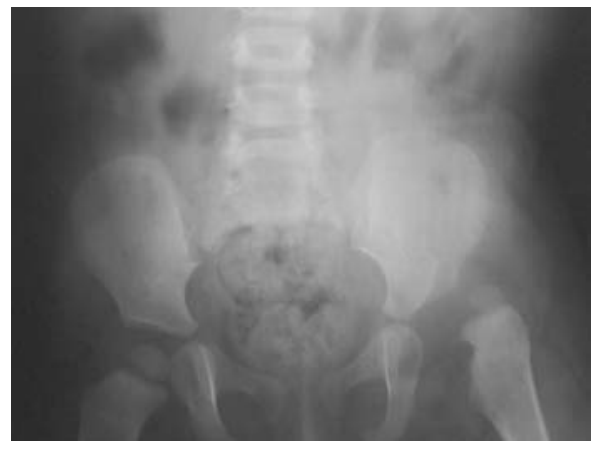

Fig. 2a

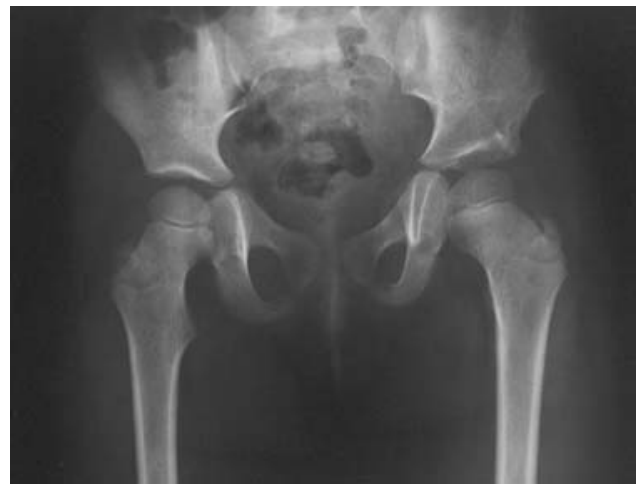

Fig. 2c

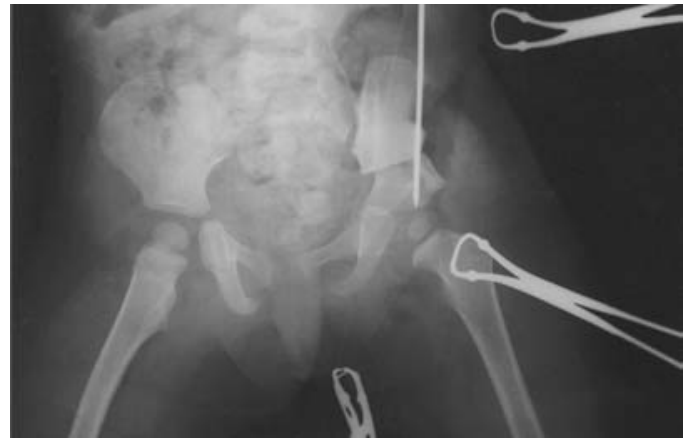

Fig. 2b

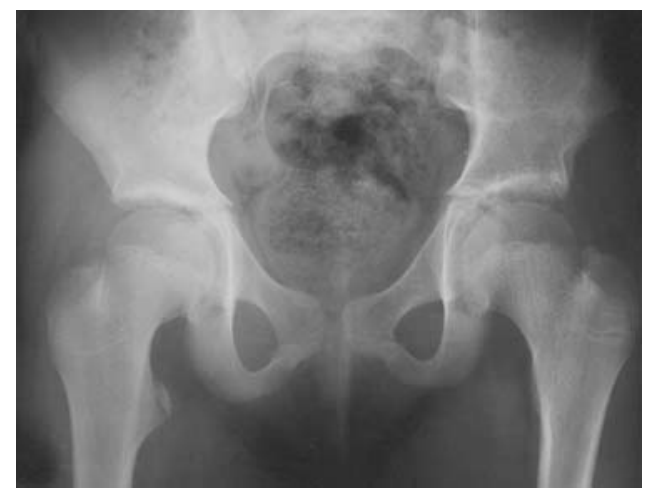

Fig. 2d

Radiographs of an 18-month-old girl with dislocation of the left hip showing a) the pre-operative view, b) during the operation, c) three years later and d) nine years later with excellent results clinically and radiologically.

radiologically Severin class II. Acetabular irregularity was noted in one hip and a mild coxa valga deformity in two although Shenton's line was normal.

Leg lengthening of less than $1 \mathrm{~cm}$ was present in two hips at the final follow-up, but gait was normal and the Trendelenburg test negative. ${ }^{16}$

In the three patients with bilateral dislocations, the contralateral hips underwent innominate osteotomy at a mean of 19.6 months (11 to 36 ) after the initial operation. In these, the radiological results were rated as class I, class II and class III. The clinical results were excellent in one hip and good in two.

\section{Discussion}

The aim of treatment in developmental dysplasia of the hip is to achieve stable concentric reduction as early as possible. The medial approach requires minimum soft-tissue dissection and allows direct access to structures which can prevent concentric reduction. Obstacles to concentric reduction such as the iliopsoas tendon, a constricted inferomedial capsule, a hypertrophied ligamentum teres, the transverse acetabular ligament and a hypertrophied pulvinar are released easily through this approach. Adductor tenotomy, if necessary, can be performed through the same incision. Konigsberg et $\mathrm{al}^{3}$ consider medial open reduction easier to perform than an anterolateral open reduction for
Table I. The mean (range) acetabular, centre-edge (CE) and neck-shaft angles

\begin{tabular}{|c|c|c|c|}
\hline & $\begin{array}{l}\text { Acetabular } \\
\text { angle( }\left(^{\circ}\right)\end{array}$ & CE angle $\left({ }^{\circ}\right)$ & Neck-shaft angle $\left({ }^{\circ}\right)$ \\
\hline Before operation & 33.4 (20 to 48 ) & - & 151 (135 to 178$)$ \\
\hline \multicolumn{4}{|l|}{ Post-operative } \\
\hline 1 year & 15.4 (5 to 25$)$ & $26.4(10$ to 40$)$ & $145(130$ to 160$)$ \\
\hline 2 years & 13.9 (8 to 38$)$ & $27.9(15$ to 40$)$ & $143(130$ to 165$)$ \\
\hline At last follow-up & 10.7 (5 to 24$)$ & 34.2 (20 to 44$)$ & 136 (128 to 148$)$ \\
\hline
\end{tabular}

the experienced hip surgeon. We have been using this approach for 25 years.

Two major disadvantages of the medial approach have been reported. First, there is the risk of injury to the medial circumflex artery and the development of avascular necrosis and secondly, the inability to perform a capsulorrhaphy which can increase the risk of residual subluxation or redislocation.

The reported incidence of avascular necrosis after the medial approach ranges from $0 \%$ to $66 \% .^{1,4,5,11,17-19} \mathrm{~A}$ high incidence of this serious complication has been reported after delayed surgical reduction, ligation of the medial femoral circumflex vessels and following previous failed closed reduction. ${ }^{3,5,18,20}$ Salter and Dubos ${ }^{9}$ reported avascular necrosis of the femoral head in $5.7 \%$ of dislocated hips in their series, but not in subluxed hips treated by 
innominate osteotomy without open reduction. For this reason, they thought that avascular necrosis was a complication of the open reduction rather than the osteotomy. Paterson ${ }^{21}$ reported that the risk of avascular necrosis was extremely high when open reduction (by the anterior approach) was combined with innominate osteotomy. He considered that open reduction combined with innominate osteotomy should not be carried out simultaneously.

In our study, no avascular necrosis was seen, but the number of patients in our series was small. Most of the hips had low dislocation (11 of 15 ), and there was no history of any failed previous treatment. In addition, we think that the avoidance of a T-shaped capsular incision, extensive capsular dissection and ligation of circumflex vessels during the medial approach is important in determining the low incidence of avascular necrosis.

Another complication of the medial approach is the need for a secondary procedure for residual dysplasia. Mankey et $\mathrm{al}^{6}$ reported that $33 \%$ of hips reduced by the medial approach required further pelvic osteotomies. Danielsson ${ }^{22}$ reported that more than half of the patients who were older than 12 months, needed additional surgery. Other authors have reported the incidence for secondary procedures after medial open reduction to be between $20 \%$ and $46 \% .^{3-5,23}$ We therefore thought that a single-stage open reduction through a medial approach combined with an innominate osteotomy would reduce the incidence of residual dysplasia in hips with an acetabular angle greater than $35^{\circ}$ on the preoperative radiograph and in those with instability after medial open reduction. To our knowledge, no similar combined technique in a single session has been previously reported.

Salter's innominate osteotomy was originally advocated for children between 18 months and six years of age. By contrast, Huang and Wang ${ }^{24}$ reported good results with open reduction and Salter's osteotomy in patients of walking age but younger than 18 months. In our study, we did not observe any problem related to Salter's osteotomy in children less than 18 months of age.

Salter and Dubos ${ }^{9}$ advised that a capsulorrhaphy should be performed in dislocated hips because of instability. They also reported a redislocation rate of $5.6 \%$ and a resubluxation rate without capsulorrhaphy of $14.3 \%$. Lejman, Strong and Michno ${ }^{25}$ compared the results of capsulorrhaphy and capsulectomy after innominate osteotomy and femoral osteotomy and reported redislocation in three of the patients with capsulorrhaphy, but in none of those with capsulectomy. In our series, no hips required secondary intervention for resubluxation or redislocation. We consider that sufficient stability can be achieved with innominate osteotomy without capsulorrhaphy in children of less than 30 months of age.

We believe that extensive capsular dissection during capsulorrhaphy may cause periarticular adhesion and fibrosis leading to limitation of movement of the hip after the anterolateral approach. A smaller anterolateral incision can be used with less extensive dissection when innominate osteotomy is performed without an anterior open reduction. The disadvantage of our combined technique is the need for two separate incisions.

No benefits in any form have been received or will be received from a commer cial party related directly or indirectly to the subject of this article.

\section{References}

1. Ferguson AB. Primary open reduction of congenital dislocation of the hip using a median adductor approach. J Bone Joint Surg [Am] 1973;55-A:671-89.

2. Diepstraten AFM. Open reduction of congenital hip dislocation: advantages of the Ferguson medial approach. Acta Orthop Scand 1985;56:32-3.

3. Konigsberg DE, Karol LA, Colby S, O'Brien S. Results of medial open reduction of the hip in infants with development dislocation of the hip. J Pediatr Orthop 2003;23: $1-9$

4. Mergen E, Adyaman H, Omeroglu H, Erdemli B, Isiklar U. Medial approach open reduction for congenital dislocation of the hip using the Ferguson procedure: a review of 31 hips. Arch Orthop Trauma Surg 1991;110:169-72.

5. Castillo R, Sherman FC. Medial adductor open reduction for congenital dislocation of the hip. J Pediatr Orthop 1990;10:335-40.

6. Mankey MG, Arntz GT, Staheli LT. Open reduction through a medial approach for congenital dislocation of the hip: a critical review of the Ludloff approach in sixty-six hips. J Bone Joint Surg [Am] 1993;75-A:1334-45.

7. Barrett WP, Staheli LT, Chew DE. The effectiveness of the Salter innominate osteotomy in the treatment of congenital dislocation of the hip. J Bone Joint Surg [Am] 1986;68-A:79-87.

8. Gulman B, Tuncay IC, Dabak N, Karaismailoglu N. Salter's innominate osteotomy in the treatment of congenital hip dislocation: a long-term review. J Pediatr Orthop 1994;14:662-6.

9. Salter RB, Dubos JP. The first fifteen years personal experience with innominate osteotomy in the treatment of congenital dislocation and subluxation of the hip. Clin Orthop 1974:98:72-103.

10. Waters P, Kurica K, Hall J, Micheli LJ. Salter innominate osteotomies in congenital dislocation of the hip. J Pediatr Orthop 1988:8:650-5.

11. Berkeley ME, Dickson JH, Cain TE, Donovan MM. Surgical therapy for congenital dislocation of the hip in patients who are twelve to thirty-six months old. J Bone Joint Surg [Am] 1984;66-A:412-20

12. Severin E. Contribution to the knowledge of congenital dislocation of the hip joint late results of closed reduction and arthrographic studies of recent cases. Acta Chir Scand 1941;63(Suppl):84

13. Tönnis D. Congenital dysplasia and dislocation of the hip in children and adults. Berlin: Springer-Verlag, 1987:83.

14. Ogata S, Moriya $\mathbf{H}$, Tsuchiya $\mathbf{K}$, et al. Acetabular cover in congenital dislocation of the hip. J Bone Joint Surg [Br] 1990;72-B:190-6

15. Salter RB, Kostuik J, Dallas S. Avascular necrosis of the femoral head as a complication of treatment of congenital dislocation of the hip in younger children: a clinical and experimental investigation. Can J Surg 1969;12:44-61.

16. Tachdjian MO. Paediatric orthopaedics. Vol. 1, Second ed. Philadelphia: W. B. Saunders C0, 1990:297-549.

17. Staheli LT. Medial approach open reduction for congenitally dislocated hips: a critical analysis of forty cases. In: Tachdjian M0, ed. Congenital dislocation of the hip. New York: Churchill Livingstone, 1982:295-303.

18. Kalamchi A, Schmidt TL, MacEwen GD. Congenital dislocation of the hip: open reduction by the medial approach. Clin Orthop 1982;169:127-32.

19. Tumer Y, Ward WT, Grudziak J. Medial open reduction in the treatment of developmental dislocation of the hip. J Pediatr Orthop 1997;17:176-80.

20. Herring JA. Tachdijan's pediatric orthopaedics. Vol. 1, Third ed. Philadelphia: W.B Saunders Company, 2002:513-654

21. Paterson DC. Innominate osteotomy: its role in the treatment of congenital dislocation and subluxation of the hip. Clin Orthop 1974;98:198-209.

22. Danielsson L. Late-diagnosed DDH: a prospective 11-year follow-up of 71 consecutive patients (75 hips). Acta Orthop Scand 2000;71:232-42.

23. Koizumi W, Moriya H, Tsuchiya K, et al. Ludloff's medial approach for open reduction of congenital dislocation of the hip: a 20-year follow-up. J Bone Joint Surg [Br] 1996;78-B:924-9.

24. Huang SC, Wang JH. A comparative study of nonoperative versus operative treat ment of developmental dysplasia of the hip in patients of walking age. J Pediat Orthop 1997;17:181-8

25. Lejman T, Strong M, Michno P. Capsulorrhaphy versus capsulectomy in open reduction of the hip for developmental dysplasia. J Pediatr Orthop 1995:15:98-100. 